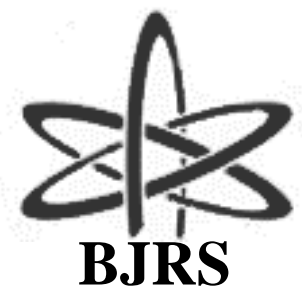

\author{
BRAZILIAN JOURNAL \\ $\mathrm{OF}$ \\ RADIATION SCIENCES \\ 08-03A (2020) 01-13
}

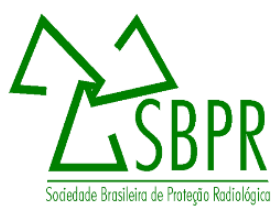

\title{
Recommendation for linearization procedure in nuclear pressure vessel-nozzle intersections
}

\author{
Figueiredo $^{\mathrm{a}}$ C.D.R., Mattar Neto ${ }^{\mathrm{a}} \mathrm{M}$. \\ ${ }^{a}$ University of São Paulo/ Nuclear and Energy Research Institute, IPEN-CNEN/SP/Nuclear Engineering Center, \\ 0550800, São Paulo, São Paulo, Brazil \\ carolinadellaricco@yahoo.com.br and mmattar@ipen.br
}

\begin{abstract}
The pressure vessel design is a fundamental step during the construction of new pressurized water reactors (PWRs). In these facilities, several safety requirements are necessary to guarantee the protection of workers, community and environment against the release of radioactive materials. The Design by Analysis is the procedure presented in the ASME Code, Section III, for nuclear components, which consist of rigorous analysis and classification of all types of stresses and loading conditions to incorporate smaller safety factors increasing the general safety. The limits presented in the ASME Code, Section III, were based on the shell theory. However, precise rules for achieving the various stress categories, in solid finite element analysis, have not been implemented yet in the code. For this reason, this work presents a methodology for the linearization procedure of elastic stresses in pressure vessel-nozzle intersections. Therefore, a vessel was modelled in tridimensional solid finite elements, analyzed and verified as a nuclear component. Then, a discussion of how to perform the code verifications was presented, as well as a mapping of stresses. The lines that were constructed in pressure vessel between transition and structural elements in the longitudinal plane $\left(0^{\circ}\right)$ and lines in structural elements in the nozzle in the transversal plane $\left(90^{\circ}\right)$ present higher stresses and are compared with the ASME Code, Section III limits.
\end{abstract}

Keywords: Elastic stress analysis, design by analysis, stress linearization, nuclear pressure vessel. 


\section{INTRODUCTION}

The pressure vessel design is a fundamental step during the construction of new pressurized water reactors (PWRs). In these facilities, it is necessary for several safety requirements that guarantee the protection of workers, community and environment against the release of radioactive materials. It is also required to ensure that the equipment can operate safely under expected and postulated loads.

In the design of nuclear pressure vessels, a widely used standard is the ASME Code [1], which the initial version, published in 1960, introduced an innovation in relation to the previous codes: the introduction of Design by Analysis. The Design by Analysis is an approach where a more detailed stress analysis and advanced techniques are used. As a result, the more reliable design is obtained, where the safety levels are increased, the safety factors are significantly reduced, and there is the prevention of the main failure modes.

The Design by Formula, the approach used up them, is a procedure frequently used in older versions of the code. It is based on shell stress distribution formulas and applied to a limited number of sections located in regular geometries. The used safety factors are higher, and in the points not covered by the formulas, details rules are applied.

In 1955, committees aimed to reevaluate and propose new criteria for establishing the limit stresses based on new knowledge were created. These committees were asked to develop a new section of the Code. In this approach (Design by Analysis), a higher number of failure modes than the previous Code version are considered, establishing safety margins. Therefore, it requires a more rigorous analysis and classification of all types of stresses and loading conditions in order to avoid the failure modes predicted for pressure vessels. In addition, it is desired to incorporate smaller safety factors than the ones used up to them.

Along with the advancement of technology, the Design by Analysis began to use the Finite Element Method. The use of three-dimensional models by applying the finite element analysis makes possible the analysis of more complex models. Nonetheless, the difficulty in evaluating the results by a solid finite element analysis and comparing them with the allowed limits has increased once that precise rules for achieving the various stress categories present in the ASME code [1] 
have not been implemented in the code. The presented recommendations are limited to some geometries and load conditions, commonly the axisymmetric conditions. To study those problems, a research project was instituted by PVRC called "WRC bulletin 429: 3D Stress Criteria Guidelines for Application" [2], which has the objective of helping with those difficulties, so the problems are modeled with solid finite elements and the stress linearized, separated and classified by ASME Code.

\section{METHODOLOGY}

The methodology applied in the current study addresses stress classification in pressure vesselnozzle intersection. It was developed according to references [2], [3], and [4].

\subsection{Stress Categorization and Classification}

The ASME categorization consists of identifying the stresses as primary stress $(\mathrm{P})$, secondary stress $(\mathrm{Q})$, or peak stress $(\mathrm{F})$.

The primary stress is the one caused by mechanical loads and it is limited in order to avoid plastic collapse. The primary stress can be classified as general membrane stress $\left(\mathrm{P}_{\mathrm{m}}\right)$, local membrane stress $\left(\mathrm{P}_{1}\right)$ and bending stress $\left(\mathrm{P}_{\mathrm{b}}\right)$. Both membrane stresses $\mathrm{P}_{\mathrm{m}}$ and $\mathrm{P}_{1}$ corresponds to the average stress in the thickness of the analyzed component. Still, the local membrane stress $\left(\mathrm{P}_{1}\right)$ is produced by mechanical loading and associated with a primary together with a discontinuity effect. The bending stress $\left(\mathrm{P}_{\mathrm{b}}\right)$ is associated with the linear variation of the stress in the thickness.

The secondary stress is the one that is present in strain compatibility, related to the linear stress portion, and the limits associated with it have propose to avoid the accumulation of plastic deformation under cyclic load (ratchetting).

The peak stress is the difference between total and the sum of membrane plus bending stress, commonly related to fatigue stress. 


\subsection{Stress Classification Lines (SCL)}

The stress classification lines (SCL), according to WRC-429 [2], are defined by two points through the vessel thickness and should be parallel to inner, outer and middle surfaces. That is not always possible.

There are some criteria for a SCL been considered valid, which tend to ensure the inaccuracies are minimized, proposed by [2], based on its allocation and the stress distribution.

About the allocation of a SCL, it should be perpendicular to surfaces tangents and in the basic structural element and not in transition elements. The structural and transitions elements are illustrated in Figure 1. A transition element is an element that connects one structural element to another, with either constant or variable thickness.
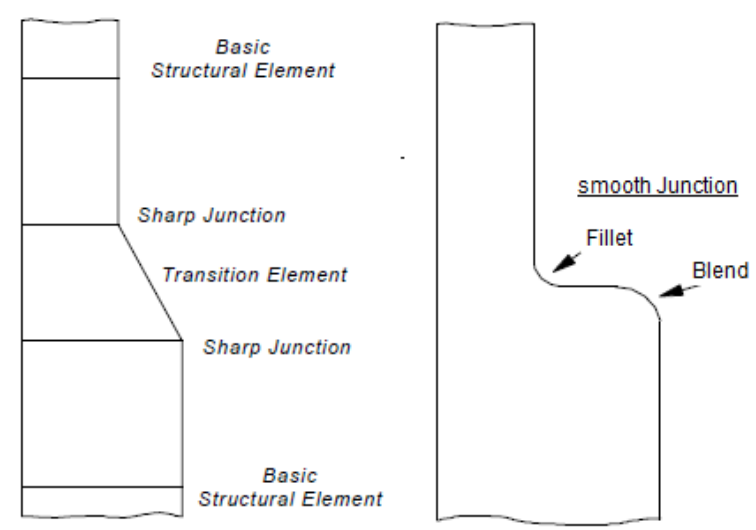

Figure 1: Structural and transition elements.

Source: ASME (2007) [1]

There are recommendations based on the stress behavior along the SCL, where the circumferential and longitudinal stresses distribution in a SCL should be linear. Through-thickness stress distribution should be linear or parabolic, depending on surface boundary conditions (zero or non-zero pressure). Moreover, through-thickness shear stress should present a parabolic shaped.

Miranda et al. [3] made a stress linearization and classification in a wye junction and it is possible to notice that lines take in transition elements presents irregular and far from the theoretical linear distribution, making the SCL in those locations not appropriated. Therefore, lines created in the present work followed those requirements within an engineering judgment level. 


\subsection{Linearization Procedure}

The linearization approach, according to ASME Code, is commonly applied in pressure vessel structural analysis. It is used due to the necessity of simulating complex models with tridimensional solid elements and comparing stress with the ASME code, which was based on shell theory for admissible limits.

The linearization is the approach used in 3D Stress Criteria Guidelines for Application. It consists of constructing a line over the element thickness and separates the stress in membrane stress (the average stress in a SCL), bending stress (the linear distribution) and peak stress (the difference between the total stress and the sum of the membrane plus the bending stress, which occurs in the edges of the SCL).

The procedure that will be used is the standard procedure used in the software Ansys [4]. It is only necessary to define a path, choosing two points that not necessary should math the nodes points. ANSYS interpolates the stress selected by the user for forty-nine points and uses equations 1,2 , and 3 to calculate the membrane, bending and peak stresses, respectively. Figure 2 shows the typical stress distribution along a line.

$$
\begin{gathered}
\sigma_{i}^{m}=\frac{1}{t} \times \int_{-\frac{t}{2}}^{\frac{t}{2}} \sigma_{i} \times d x_{s} \\
\sigma_{i 1}^{b}=\frac{-6}{t^{2}} \times \int_{-\frac{t}{2}}^{\frac{t}{2}} \sigma_{i} \times x_{s} \times d x_{s} \\
\sigma_{i 1}^{p}=\sigma_{i 1}-\sigma_{i}^{m}-\sigma_{i 1}^{b}
\end{gathered}
$$

Where :

- $\mathrm{t}=$ thickness of section, as shown in Figure 2

- $\sigma \mathrm{i}=$ stress component $\mathrm{i}$ along path from total stress distribution 
- $\mathrm{xs}=$ coordinate along path.

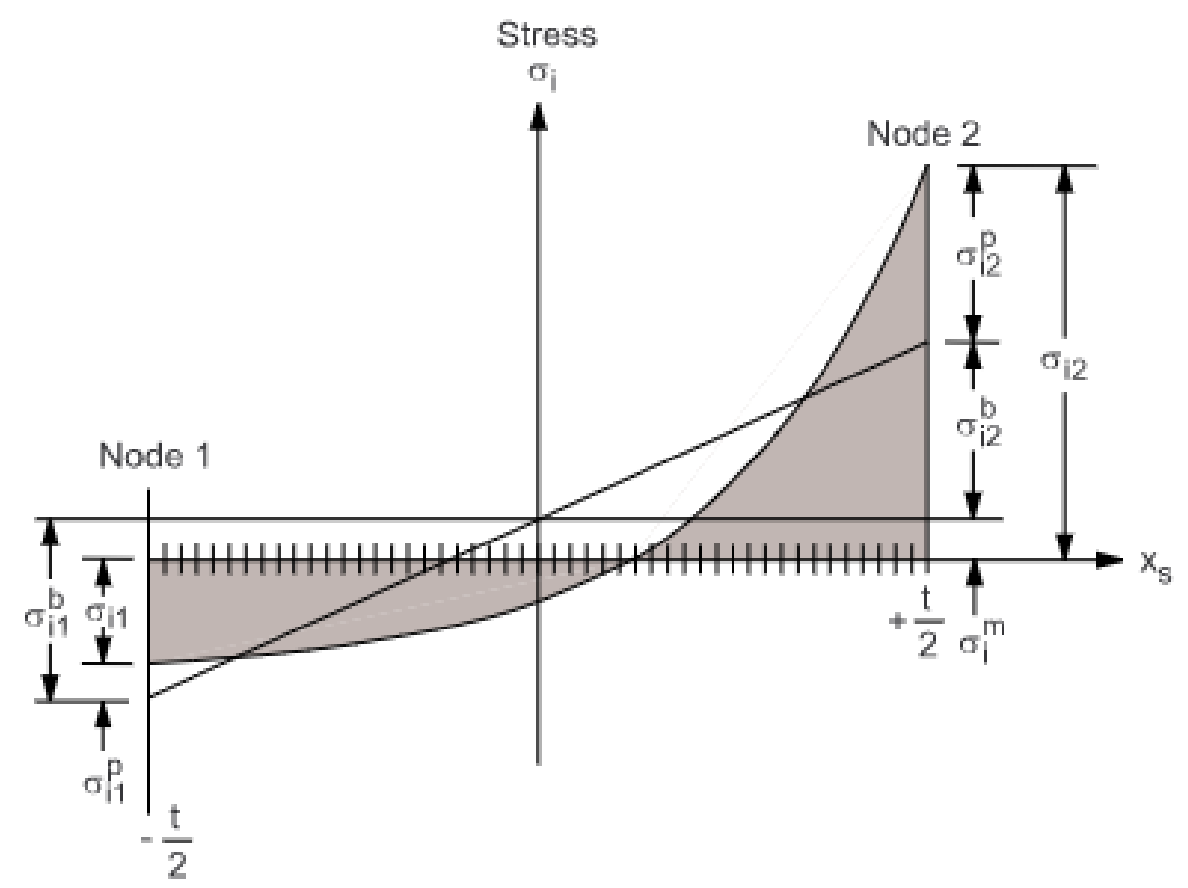

Figure 2: Typical stress distribution.

Source: Ansys (2017) [4]

\section{STUDY CASE: PRESSURE VESSEL-NOZZLE MODEL}

The study case consists of mapping and classification of the stress in a pressure vessel-nozzle intersection. A simulation was performed with the software Ansys Mechanical in Nuclear and Energy Research Institute, IPEN-CNEN/SP.

\subsection{Geometry}

The geometry used in this study is a pressure vessel-nozzle intersection and its dimensions and pressure value is present in WRC-429 as geometry 6 in cylinder-to-cylinder intersection problems. Although it is not a nuclear item, it will be analyzed according to ASME Code, Section III, for nuclear components. The geometry was modeling using Ansys Spaceclaim [5]. Even though the 
decay distance of suggested is: $2.5 \times \sqrt{R_{m} \times t}$, the distance of $3.0 \times \sqrt{R_{m} \times t}$ in this study was used to guarantee that the loads and the boundary conditions would not influence stress response in the nozzle region.

\subsection{Study of Mesh Quality}

The geometry was sliced in strategic parts to facilitate the mesh inputs and to obtain results, as shown in Figure 3.

Liping and Widera [6] makes some mesh size recommendations. In axial directions, the elements must vary $0.02 \times \sqrt{R_{m} \times t}$ in the discontinuity site to $0.5 \times \sqrt{R_{m} \times t}$ in decay distance. After that, the elements can be about $1.0 \times \sqrt{R_{m} \times t}$. For the thickness, tree elements are considered enough. So, for the first mesh created was set based on those recommendations and the mesh used in the base document, so a verification of the numerical model (loads, displacement restriction, symmetry axes) was made. The mesh was refined in order to decrease the numerical uncertainties and carry more reliability to the results without the time processing concern, increasing the element number by $50 \%$.

To get to the final and refined mesh, tree more meshes were created based on the first one. Table 1 summarized meshes information, as well as nodes and elements numbers. Table 2 brings the differences in linearized stress intensity for the seven SCL in the longitudinal plane $\left(0^{\circ}\right)$ for the four meshes.

As the refinement does not significantly affect the membrane and membrane plus bending stresses, mesh 1 was chosen, once it will bring the smallest computational cost between the options, for the same accuracy.

Table 1: Meshes information.

\begin{tabular}{cccc}
\hline Mesh & Nodes & Elements & $\begin{array}{c}\text { Elements thru } \\
\text { the thickness }\end{array}$ \\
\hline 1 & 341628 & 67497 & 3 \\
2 & 483173 & 100528 & 4 \\
3 & 657432 & 141310 & 5 \\
4 & 973078 & 214050 & 6 \\
\hline
\end{tabular}


Table 2: Differences between meshes.

\begin{tabular}{|c|c|c|c|c|c|c|c|c|}
\hline \multirow[b]{2}{*}{ SCL } & \multirow[b]{2}{*}{ Component } & \multicolumn{7}{|c|}{ Stress Intensity (MPa) } \\
\hline & & Mesh 1 & Mesh 2 & Diff $(\%)$ & Mesh 3 & Diff (\%) & Mesh 4 & $\begin{array}{l}\text { Diff } \\
(\%)\end{array}$ \\
\hline \multirow{3}{*}{1} & $\mathrm{M}$ & 185.62 & 185.63 & 0.01 & 185.63 & 0.00 & 185.6 & 0.02 \\
\hline & $\mathrm{M}+\mathrm{Bo}$ & 149.67 & 149.66 & 0.01 & 149.67 & 0.01 & 149.65 & 0.01 \\
\hline & $\mathrm{M}+\mathrm{Bi}$ & 221.57 & 221.59 & 0.01 & 221.6 & 0.00 & 221.55 & 0.02 \\
\hline \multirow{3}{*}{2} & M & 187.37 & 187.38 & 0.01 & 187.38 & 0.00 & 187.36 & 0.01 \\
\hline & $\mathrm{M}+\mathrm{Bo}$ & 144.61 & 144.61 & 0.00 & 144.62 & 0.01 & 144.6 & 0.01 \\
\hline & $\mathrm{M}+\mathrm{Bi}$ & 230.14 & 230.15 & 0.00 & 230.14 & 0.00 & 230.11 & 0.01 \\
\hline \multirow{3}{*}{3} & M & 194.09 & 194.1 & 0.01 & 194.1 & 0.00 & 194.08 & 0.01 \\
\hline & $\mathrm{M}+\mathrm{Bo}$ & 139.35 & 139.36 & 0.01 & 139.37 & 0.01 & 139.36 & 0.01 \\
\hline & $\mathrm{M}+\mathrm{Bi}$ & 248.83 & 248.84 & 0.00 & 248.83 & 0.00 & 248.8 & 0.01 \\
\hline \multirow{3}{*}{4} & M & 208.86 & 208.93 & 0.03 & 208.85 & 0.04 & 208.92 & 0.03 \\
\hline & $\mathrm{M}+\mathrm{Bo}$ & 135.03 & 134.95 & 0.06 & 134.95 & 0.00 & 134.91 & 0.03 \\
\hline & $\mathrm{M}+\mathrm{Bi}$ & 282.76 & 283.00 & 0.08 & 282.83 & 0.06 & 283.01 & 0.06 \\
\hline \multirow{3}{*}{5} & M & 96142.00 & $\begin{array}{c}96208.0 \\
0\end{array}$ & 0.07 & $\begin{array}{c}96228.0 \\
0\end{array}$ & 0.02 & $\begin{array}{c}96254.0 \\
0\end{array}$ & 0.03 \\
\hline & $\mathrm{M}+\mathrm{Bo}$ & 126.53 & 126.5 & 0.02 & 126.49 & 0.01 & 126.54 & 0.04 \\
\hline & $\mathrm{M}+\mathrm{Bi}$ & 66056.00 & 66.26 & 0.31 & $\begin{array}{c}66324.0 \\
0\end{array}$ & 0.10 & $\begin{array}{c}66337.0 \\
0\end{array}$ & 0.02 \\
\hline \multirow{3}{*}{6} & M & 116.25 & 116.24 & 0.01 & 116.24 & 0.00 & 116.23 & 0.01 \\
\hline & $\mathrm{M}+\mathrm{Bo}$ & 148.99 & 148.97 & 0.01 & 148.95 & 0.01 & 148.93 & 0.01 \\
\hline & $\mathrm{M}+\mathrm{Bi}$ & 83508.00 & $\begin{array}{c}83515.0 \\
0\end{array}$ & 0.01 & 83.53 & 0.02 & $\begin{array}{c}83536.0 \\
0\end{array}$ & 0.01 \\
\hline \multirow{3}{*}{7} & M & 112.73 & 112.66 & 0.06 & 112.68 & 0.02 & 112.59 & 0.08 \\
\hline & $\mathrm{M}+\mathrm{Bo}$ & 152.93 & 152.95 & 0.01 & 152.91 & 0.03 & 152.92 & 0.01 \\
\hline & $\mathrm{M}+\mathrm{Bi}$ & 72532.00 & $\begin{array}{c}72369.0 \\
0\end{array}$ & 0.22 & $\begin{array}{c}72446.0 \\
0\end{array}$ & 0.11 & $\begin{array}{c}72271.0 \\
0\end{array}$ & 0.24 \\
\hline
\end{tabular}

\subsection{SCLs Construction}

In order to classify the stresses in the pressure vessel-nozzle intersections, seven lines were created along with the discontinuities places, four in the pressure-vessel and three in the nozzle, every $10^{\circ}$. As the recommendation suggests creating lines in structural elements, no line was created in transition elements except for the SCLs 4 and 5, which are between structural and transition elements and may be or not consider valid according to the WRC-429 [2] recommendations. In the 
pressure-vessel, SCL 1, 2, 3 and 4 were created separated from each other in a distance of $0.5 \times \sqrt{R_{m} \times t}$ and SCL 5, 6 and 7 from nozzle were separated in $1.5 \times \sqrt{R_{m} \times t}$.

Figure 3 illustrates where the SCLs were taken, labeled in red, in the perpendicular of the axis X plan $\left(0^{\circ}\right)$. Figure 3 also shows the other plans, marked in blue, where the SCLs were taken in the same distance from the transition element (discontinuities).

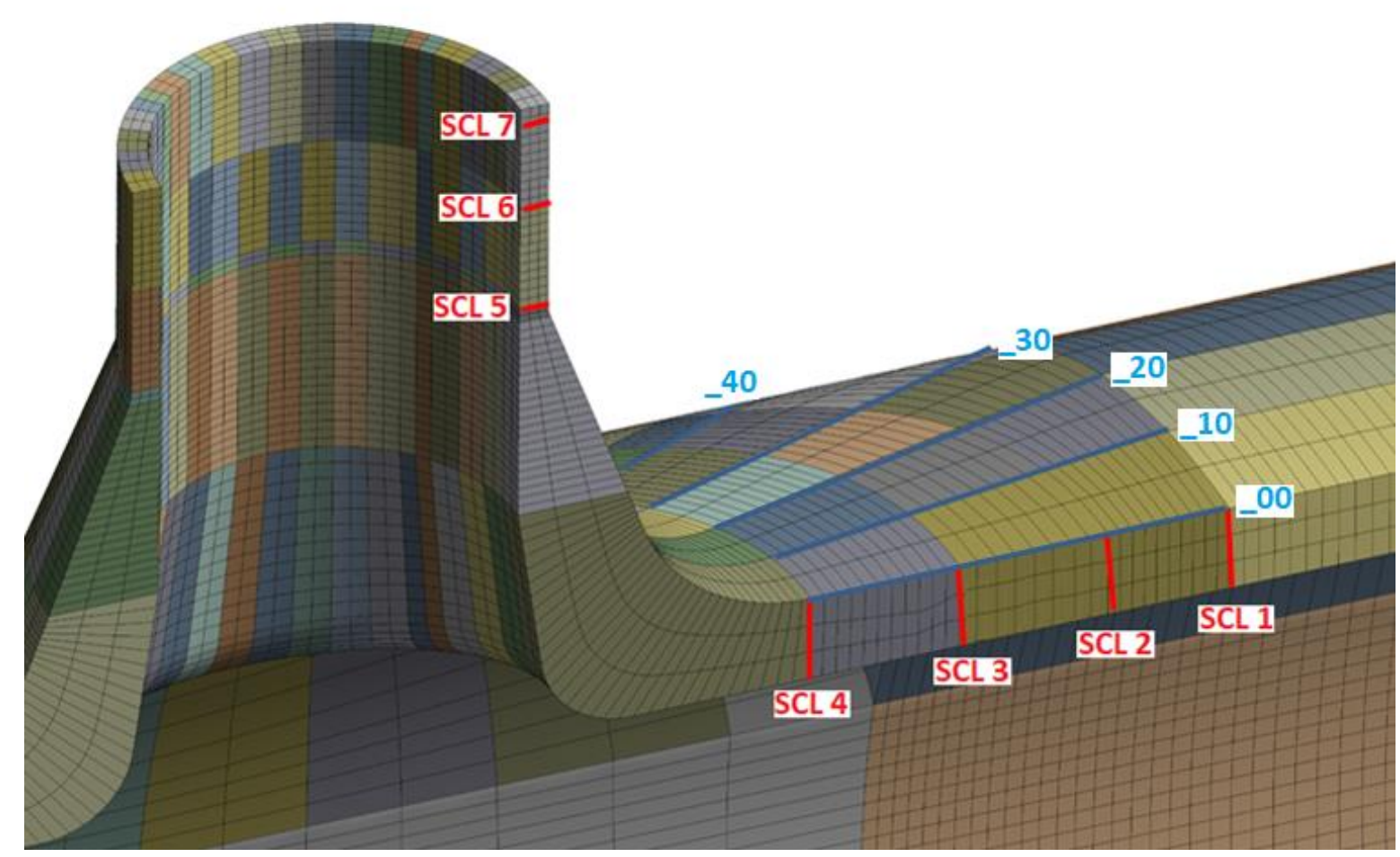

Figure 3: Mesh used in simulation and choice of SCLs.

Source: Authors

\subsection{Results and Discussion}

The stress intensity is linearized for the seven SCL, along ten plan angles ( 0 to $90^{\circ}$ ), as Figure 4 illustrates. Therefore, it is possible to map the stress behavior along the proximities of the discontinuities. SCL 1, 2, 3, and 4, localized in the pressures-vessel, presents the inside membrane plus bending stress bigger than the outside one at $0^{\circ}$. As the plane angle increase, the reverse occurs. They get the same value at an angle of about $45^{\circ}$. 
The same occurs in SCL 5, 6 and 7, localized in the nozzle. The outside membrane plus bending stress is bigger than the inside membrane plus bending stress at $0^{\circ}$, and as long as the angle is increased, the reverse occurs. They get the same value at an angle of about $40^{\circ}$.

Figure 5 shows the stress behavior along the angle variation for the SCL presents in pressurevessel that presents the highest membrane and membrane plus bending stress: SCL 4.

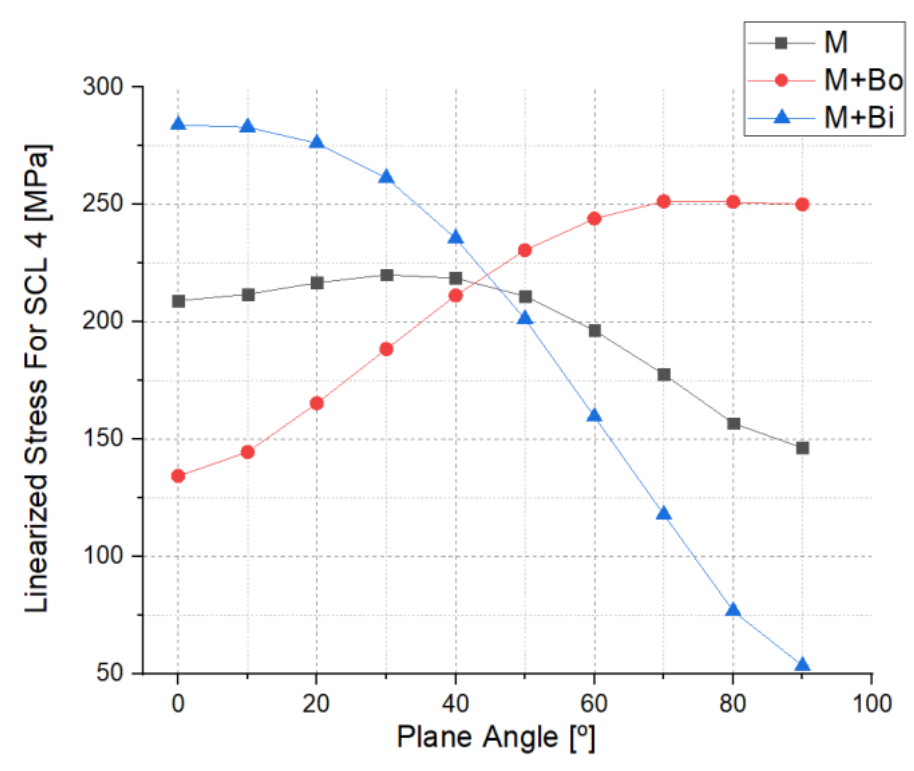

Figure 5: Stress behavior for SCL 4 [MPa].

Source: Authors

Figure 6 shows the stress behavior along the angle variation for the SCL presents in the nozzle that presents the highest membrane and membrane plus bending stress: SCL 6 and 7, respectively.

Observing the linearized stress results for each SCL along the angles and the stress behavior presented in the graphics from Figure 5 and Figure 6, it is possible to conclude that, for this case, the highest membrane plus bending stress is always applied in angle 0 or $90^{\circ}$. 

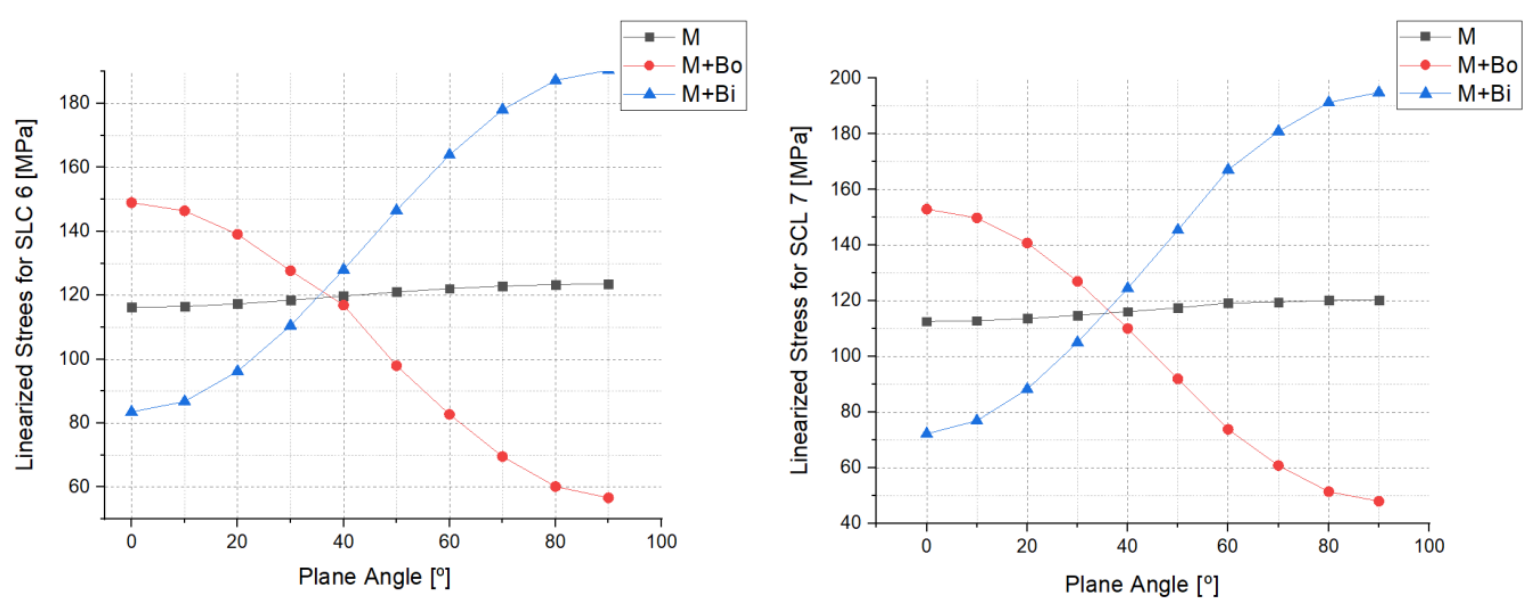

Figure 6: Stress behavior for SCL 6 and 7 [MPa].

Source: Authors

\subsection{Stress Categorization and Comparison with the ASME Limits}

Table 3 brings the highest values of membrane and membrane plus bending stress that each component is exposed. The material considered was the usual steel used in the pressure vessel construction, SA508 Class 3. Its yield stress, from ASME proprieties [7], for temperature about $300^{\circ} \mathrm{C}$, is $259.5 \mathrm{MPa}$. This way, the maximum allowable stress $\mathrm{Sm}=173 \mathrm{MPa}$.

Table 3: Stress Classification, in MPa.

\begin{tabular}{ccccccc}
\hline & Component & SCL & SI (MPa) & Classification & ASME Limit & Verification \\
\hline Pressure- & $\mathrm{M}$ & $4 \_30$ & 220.12 & $\mathrm{Pl}$ & $1.5 \times \mathrm{Sm}=275 \mathrm{MPa}$ & Pass \\
vessel & $\mathrm{M}+\mathrm{Bi}$ & $4 \_00$ & 283.91 & $\mathrm{P}+\mathrm{Q}$ & $3.0 \times \mathrm{Sm}=550 \mathrm{MPa}$ & Pass \\
& $\mathrm{M}$ & $6 \_90$ & 123.55 & $\mathrm{Pl}$ & $1.5 \times \mathrm{Sm}=275 \mathrm{MPa}$ & Pass \\
Nozzle & $\mathrm{M}+\mathrm{Bi}$ & $7 \_90$ & 194.91 & $\mathrm{P}+\mathrm{Q}$ & $3.0 \times \mathrm{Sm}=550 \mathrm{MPa}$ & Pass \\
\hline
\end{tabular}

The stress classification is done based on the SCL location. In pressure-vessel, the highest membrane and membrane plus stresses are localized in SCL 4. As SCL 4 is close to the discontinuities, between structural and transition elements, the stresses may present a secondary stress portion. It is classified as primary location stress $\mathrm{Pl}$ and primary plus secondary stress $\mathrm{P}+\mathrm{Q}$, respectively. 
In the nozzle, the highest membrane stress is in SCL 6 and is classified as primary membrane stress Pm. The highest membrane plus bending stresses are localized in SCL 7 and it is classified as primary membrane plus primary bending $\mathrm{Pm}+\mathrm{Pb}$. As both are far from discontinuities, the stresses are caused only due to mechanical loads and are classified as primary. ASME limits the Pm, Pl, Pm $+\mathrm{Pb}$ and $\mathrm{P}+\mathrm{Q}$ stresses as Sm, 1.5 x Sm, 1.5 x Sm and 3.0 x Sm, respectively.

It is possible to notice that the highest stress in the nozzle is in the transversal plane $\left(90^{\circ}\right)$ and membrane plus bending occurs in the longitudinal plane. The vessel's highest membrane stress occurs in a $30^{\circ}$ plane, although the difference between membrane stress of SCL 4_00 and SCL 4_30 is about $5 \%$.

\section{CONCLUSION}

The study presents the verification of pressure vessel-nozzle intersection stresses done according to the ASME Code as well as a mapping of stress. Only stresses due to the internal pressure were considered, once the aim is to emphasize the procedure of the stress classification and linearization. These procedures are common in the nuclear area, and it is still an open issue. The SCLs have their stress classified based on their location: lines taken out of discontinuities have their membrane stress classified as $\mathrm{Pm}$ and membrane plus bending stress classified as $\mathrm{Pm}+\mathrm{Pb}$. Lines near the discontinuities have their stress classified as $\mathrm{Pl}$ for membrane stress and $\mathrm{P}+\mathrm{Q}$ for membrane plus bending stress. Finally, can be highlighted that lines constructed on pressure vessel between transition and structural elements on the longitudinal plane $\left(0^{\circ}\right)$ and lines constructed on the nozzle in structural elements on the transversal plane $\left(90^{\circ}\right)$ present higher stresses. 


\section{ACKNOWLEDGMENT}

The authors are grateful to Instituto de Pesquisas Energéticas e Nucleares, IPEN-CNEN/SP (Nuclear and Energy Research Institute, in english), for the support given for this work, to Dr. Javier González Mantecón and Altair Faloppa for his helpful writing comments, as well as to Conselho Nacional de Desenvolvimento Científico e Tecnológico, CNPq (Brazilian Council for Scientific and Technological Development, in english) for the funding.

\section{REFERENCES}

[1] ASME - American Society of Mechanical Engineers. ASME Boiler \& Boiler \& Pressure Vessel Code, Section III, Division 1, Subsection NB - Class 1 Components, 2007.

[2] HECHMER, J. L.; HOLlingeR, G. L. 3D Stress Criteria - Guidelines for Application. Welding Research Council, Inc., Bulletin WRC 429, ISSN 0043-2326 / ISBN 1-58145-436-8, Feb. 1998, Welding Research Council, Inc., N. York, USA, 1998.

[3] MIRANDA. C. A. J.; FAlOPPA. A. A.; NETO. M. M.; FAINER. G. ASME Stress Linearization and Classification - A Discussion Based on a Case Study. In: INTERNATIONAL NUCLEAR ATLANTIC CONFERENCE, 2011. Belo Horizonte. Annals... Belo Horizonte: Comissão Nacional de Energia Nuclear, 2011. Pag. 1-10

[4] ANSYS Inc.. ANSYS Structural Analysis Guide \& Theory Reference Manual, APDL v18.2, 2017.

[5] Ansys Inc. ANSYS Spaceclaim Help Manual v18.2, 2018.

[6] LIPING, X and WIDERA, G.E.O. Guidelines for FEA Modeling of Cylinder-To-Cylinder Intersection. July San Diego, California USA. PVP-Vol. 477, 25-29, 2004.

[7] ASME - American Society of Mechanical Engineers. ASME Boiler \& Pressure Vessel Code, Section II, Part D - Properties (Materials), 2007. 